\title{
STUDY ON THE APPLICATION OF GALLIUM NITRIDE TRANSISTORS IN POWER ELECTRONICS
}

\author{
Renan R. Duarte $^{1}$, Guilherme F. Ferreira ${ }^{1}$, Marco A. Dalla Costa ${ }^{1}$, Carlos H. Barriquello ${ }^{1}$, J. Marcos \\ Alonso $^{2}$ \\ ${ }^{1}$ Universidade Federal de Santa Maria, Santa Maria - RS, Brazil \\ ${ }^{2}$ Universidad de Oviedo, Gijón, Spain \\ e-mail: \{renan.duarte, guilhermefarias, marcodc, barriquello\}@gedre.ufsm.br, marcos@uniovi.es
}

\begin{abstract}
Wide bandgap semiconductors have emerged as an attractive option for silicon (Si) replacement in the recent years. Among the new materials, gallium nitride ( $\mathrm{GaN}$ ) has been considered as the most promising candidate. This paper presents an overview of the GaN technology in power electronics. The review focuses on the main aspects of GaN transistors, such as electrical, thermal and economical characteristics. A comparison between $\mathrm{Si}$ and GaN switching devices in a family of synchronous buck converters designed for LED lighting applications is also presented. This comparison was performed using synchronous buck converters, designed under same parameters, at five different switching frequencies, ranging from $100 \mathrm{kHz}$ to $1 \mathrm{MHz}$. Efficiency and temperatures were recorded. GaN based converters presented higher efficiency and lower operating temperatures in all cases, with a maximum efficiency of $96.8 \%$ and a minimum of $94.5 \%$. Besides, Si-based converters exhibited a higher performance degradation as switching frequency and dead time increase.
\end{abstract}

Keywords - GaN, Gallium Nitride, GaN Transistors, LEDs, Switching Power Supply.

\section{INTRODUCTION}

Since the beginning of power electronics with the development of the mercury-arc rectifier, used in conversion from AC to DC in the railways of the 1920s [1], the world has been transformed by innovations provided by the ability to process energy through electronic circuits. However, only with the development of the silicon ( $\mathrm{Si}$ ) transistor in the 1940s [2], and especially the silicon metal-oxide field effect transistor (MOSFET) in the 1970s [3], the creation of more compact and efficient systems based on switching converters became possible.

It is estimated that, by $2030,80 \%$ of the world's electricity will be, somehow, processed by switched converters [4]. Thereby, it is expected the power semiconductor market surpass $\$ 17 \mathrm{~B}$ by 2020 , driven, in particular, by the worldwide trend for more energy efficient devices [5].

The development of more efficient and compact circuits depends on improvements in the semiconductor devices used [6]. The increase of switching frequency has been a recurrent alternative because it allows the miniaturization of passive

Manuscript received 27/05/2017; first revision 17/07/2017; accepted for publication 18/09/2017, by recommendation of Editor Marcelo Cabral Cavalcanti. components in the circuit [7]. However, it is necessary to minimize losses in the semiconductors, since these are one of the major limiting factors in power converters [8].

Many advances have been made in $\mathrm{Si}$ semiconductor manufacturing technology, allowing circuits to boost their power density in a virtually linear trend, increasing about tenfold since they appeared in the market [9]. However, as $\mathrm{Si}$ technology approaches its theoretical limits of performance, the need for a substitute of the same relevance becomes more evident. The use of new wide bandgap semiconductors such as gallium nitride $(\mathrm{GaN})$ is still rather modest. However, it is expected that this type of semiconductor will share up to $5 \%$ of the market in 2020 [5]. The substitution of Si by these new materials may result in substantial gains in converter performance in terms of efficiency, reliability, higher operating voltages and lower thermal management requirements [10], allowing the trend of miniaturization and efficiency increase of power electronics systems continue to evolve.

The replacement of Si MOSFETs by GaN-based devices in applications such as photovoltaic [11], [12], power factor correction [13], [14], audio power amplifiers [3] , envelope tracking [15], wireless energy transfer [16], [17], Light Distancing and Ranging (LiDAR) [18] and motor drivers [19] was already demonstrated.

In this scenario, the paper intends to highlight the potential of GaN to take Si's place in the electronic market in the near future through an overview of main properties and a performance comparison between both technologies.

This work is organized as follows: Section II presents a comparison of materials used in the fabrication of semiconductor devices, showing the relationship between each characteristic of the material and its influence in the produced device. The concept of theoretical limit for a semiconductor technology is also presented; GaN semiconductors and their types, characteristics and constructive aspects are discussed in Section III. Design challenges posed by the emergence of this new technology are introduced in Section IV. Section V shows economical aspects related with the development of GaN-based devices. An experimental comparison between Siand GaN-based transistors in a DC-DC converter for lighting applications is made in Section VI. Finally, in Section VII, the conclusions of this paper are presented.

\section{MATERIAL SELECTION FOR POWER SEMICONDUCTORS}

The quality and characteristics of a semiconductor device are determined by the characteristics of the material used 
in the fabrication process [3], [20]. Table I summarizes some of the key parameters of $\mathrm{Si}, \mathrm{SiC}$ and $\mathrm{GaN}$ [3], [21]. These are some of the most commonly used materials in the power semiconductor industry. In the next subsections, each parameter will be discussed and its implications in the final device will be evaluated.

\section{TABLE I}

Properties of $\mathrm{Si}, \mathrm{SiC}$ and $\mathrm{GaN}$

\begin{tabular}{lcccc}
\hline Parameter & Symbol & Si & SiC & GaN \\
\hline Bandgap $(\mathrm{eV})$ & $E_{g}$ & 1.12 & 3.26 & 3.39 \\
\hline Electron mobility $\left(\mathrm{cm}^{2} / \mathrm{V} \cdot \mathrm{s}\right)$ & $\mu_{n}$ & 1400 & 950 & 1500 \\
\hline Critical field $(\mathrm{MV} / \mathrm{cm})$ & $E_{c r i t}$ & 0.23 & 2.2 & 3.3 \\
\hline Permittivity & $\varepsilon_{r}$ & 11.8 & 9.7 & 9 \\
\hline Thermal conductivity $(\mathrm{W} / \mathrm{cm} \cdot \mathrm{K})$ & $\lambda$ & 1.5 & 3.8 & 1.3 \\
\hline Melting point $\left({ }^{\circ} \mathrm{C}\right)$ & - & 1414 & 2730 & 2500 \\
\hline
\end{tabular}

\section{A. Bandgap}

Semiconductor materials, at absolute zero temperature $\left(0 \mathrm{~K}\right.$ or $\left.-273.15^{\circ} \mathrm{C}\right)$, have all their electrons confined in the valence band, thus acquiring characteristics of an electrical insulator. Semiconductors can start conducting electricity, as the temperature increases, if their electrons absorb energy in order to surpass the valence band. The amount of energy required for the electrons to make this transition is called bandgap [22], [23].

This energy is related to the strength of the chemical bonds among atoms in the crystalline structure [22]. The stronger the bond, the harder it is for a free electron to move between atoms. Among the consequences of this phenomenon in power semiconductors, are the lower leakage currents and higher operating temperatures [3].

A larger bandgap allows a material to withstand higher electric fields, making possible to use a smaller semiconductor die for a given voltage. This has a direct impact on the characteristics of the device, as the smaller the die, the lower its electrical resistance and intrinsic capacitances. Consequently its efficiency will increase [21].

Materials with bandgap larger than $3 \mathrm{eV}$ are commonly called wide bandgap semiconductors [6], [10], [24], [25].

\section{B. Electron Mobility}

Electron mobility represents the velocity in which an electron can move in the material lattice when propelled by an electrical field, expressed as:

$$
\mu_{n}=\frac{v}{E}
$$

where $v$ is the drift velocity of the material and $E$ is the critical field applied.

The higher the electron mobility, the lower the resistance of the semiconductor [22]. As seen in Table I, GaN has the higher electron mobility. For this reason, GaN switches are commonly called GaN High Electron Mobility Transistors (GaN HEMTs).

\section{Critical Field}

The critical field represents the maximum electrical field the material withstands without causing avalanche breakdown [3]. For power semiconductors, this is directly related to the maximum blocking voltage $V_{B R}$, given as:

$$
V_{B R}=\frac{1}{2} w_{\text {drift }} E_{c r i t}
$$

where $w_{\text {drift }}$ is the width of the drift region.

Due to its critical field more than ten times larger than $\mathrm{Si}$, $\mathrm{SiC}$ and $\mathrm{GaN}$ semiconductors can be made with a drift region ten times smaller for the same blocking voltage [3]. Therefore, the distance between the transistor terminals can be drastically reduced, producing smaller devices with lower resistances and capacitances [25].

It is possible to evaluate the number of electrons $N_{D}$ between the two terminals (assuming an N-type semiconductor) using the Poisson equation [3]:

$$
N_{D}=\frac{\varepsilon_{0} \varepsilon_{r} E_{c r i t}}{w_{d r i f t} q} .
$$

In this equation $q$ is the charge of the electron $\left(1.6 \cdot 10^{-12}\right.$ Coulombs) and $\varepsilon_{0}$ is the permittivity of free space.

Thus, according to (3), if a material has a critical field ten times higher and, therefore, a drift region ten times smaller, the number of electrons between the terminals can be 100 times higher. This explains the superior performance of large bandgap transistor when compared to traditional Si-based devices.

\section{Theoretical Limits}

One way to translate these material parameters into a device comparison is to evaluate the theoretical limits of a semiconductor material. The ideal on-resistance of a major carrier device (as presented by [3]) is given by:

$$
R_{D S(o n)}=\frac{w_{d r i f t}}{q \mu_{n} N_{D}} .
$$

Combining (2), (3) and (4), one can obtain the specific onresistance or theoretical limit of a semiconductor technology, which is usually measured in $\Omega \cdot m^{2}$ :

$$
R_{\text {on }(s p)}=\frac{4 V_{B R}^{3}}{E_{c r i t}^{3} \varepsilon_{0} \varepsilon_{r} \mu_{n}} .
$$

Equation (5) relates the maximum blocking voltage of a device with the resistance of a specific die area. These limits are shown in Figure 1 for $\mathrm{Si}, \mathrm{SiC}$ and $\mathrm{GaN}$ along with the data of some devices of different technologies [26], [27].

It is clear that $\mathrm{GaN}$ has the best relationship between voltage and resistance. Although some Si-based devices were able to surpass its theoretical limits, this evolution took almost 30 years to occur. There are already $\mathrm{SiC}$ devices that exceed the best Si MOSFETs in terms of performance. These devices are, however, limited mostly to high voltage applications, mainly due to its production cost.

On the other hand, GaN devices have at the present time superior performance than their Si counterparts and are, still, in the early stages of development. This demonstrates all the potential of this new material to take Si place in the power electronics market in the future. 


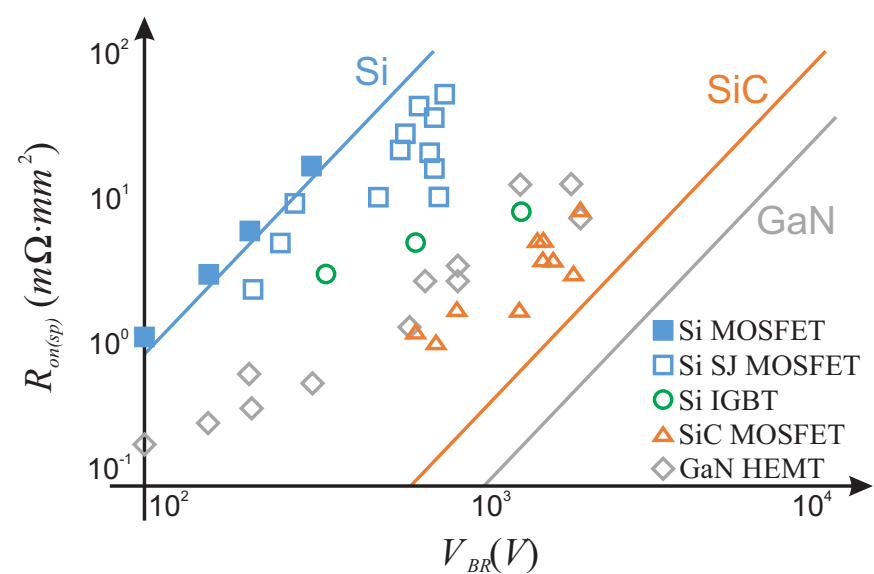

Fig. 1. Theoretical limits of $\mathrm{Si}, \mathrm{SiC}$ and $\mathrm{GaN}$ with specific onresistance of selected devices.

\section{GALLIUM NITRIDE TRANSISTORS}

The first advances in the manufacture of GaN-based transistors during the $90 \mathrm{~s}$ were focused on radiofrequency (RF) applications [28], [29] being the high electron mobility effect of gallium nitride first demonstrated in 1975 [30]. The first GaN transistors for the RF market appeared in 2004, produced by the companies Eudyna Corporation, CREE, Nitronex and RFMD [3], [31], [32].

In 2005, the process of growth GaN crystals on Si substrates was developed, making it possible the mass production of these devices using the tools already available for the manufacturing of Si semiconductors [3].

The first $\mathrm{GaN}$ transistor specifically developed to replace $\mathrm{Si}$ MOSFETs in switched applications was developed in 2009 by Efficient Power Conversion [3]. In the same year, the cascodetype GaN transistor was developed, specifically aimed at higher voltage applications [33].

There are currently three types of $\mathrm{GaN}$ transistors for power electronics: depletion, enhancement and cascode. The first two are similar to traditional P- and N-type MOSFETs, respectively. The third type consists of a hybrid topology, since it comprises in the same package a Si MOSFET and a GaN HEMT, as it will be detailed below.

\section{A. Depletion Mode}

Depletion mode $\mathrm{GaN}$ transistors, or $\mathrm{dGaN}$, are normally on devices, that is, current flows freely between drain and source terminals when no potential is applied to the gate terminal. To switch this type of device to off-state, a negative gate-source voltage needs to be applied [3].

Although having blocking voltages that can exceed $1 \mathrm{kV}$ [34], [35], in power electronics applications, this type of transistor is not recommended due to safety reasons. They are yet not commercially available as standalone devices, only demonstrated in academic papers [7], [36], [37] or used in conjunction with Si MOSFETs as it will be explained later on.

\section{B. Enhancement Mode}

Enhancement mode transistors, or eGaN, are normally off, that is, they do not present a path for conducting current between drain and source if no voltage is applied to the gate

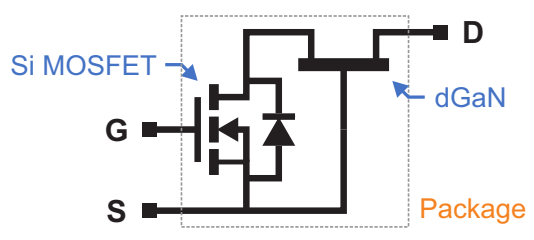

Fig. 2. Typical arrangement of a GaN-based cascode transistor.

terminal [3].

This type of transistor has a lower threshold voltage $V_{G S(t h)}$ than other semiconductors. Generally, commercial eGaNs allow a maximum driver voltage in the order of 7V [38]. For this reason, both the control circuit and the arrangement of the circuit components require special care to ensure proper operation of the switch.

\section{Cascode}

Cascode type transistors, or $\mathrm{cGaN}$, are hybrids formed from the connection of a high-voltage $\mathrm{dGaN}$ transistor with a lowvoltage Si MOSFET [33]. Figure 2 shows the schematic of this device.

This arrangement allows the development of a normally off semiconductor that withstand larger driver voltages (determined by the Si MOSFET used) [39]. The command signal is applied directly to the Si MOSFET, which controls the conduction of the GaN transistor. When in conduction, the current flows through both semiconductors and, when blocked, the voltage is applied on the GaN transistor.

In this configuration, the on-resistance of the low-voltage MOSFET is much lower than that of the GaN transistor, the latter having a dominant behavior in relation to conduction losses [39]. If a smaller voltage $\mathrm{GaN}$ transistor is used, the participation of the MOSFET in the on-resistance of the final semiconductor increases, eliminating the advantages of using a hybrid topology. For this reason, cascode transistors are only feasible for blocking voltages greater than 200V [3].

\section{DESIGN CHALLENGES}

With the use of a new and still little explored technology, there is a need to deepen the techniques used in the design of the circuits in which these new products are inserted.

It is important to emphasize that $\mathrm{GaN}$ transistors have a lateral structure, that is, the conduction of the electrons between the terminals occurs in the horizontal plane, allowing the device terminals to be placed side by side in the semiconductor die [40]. Among the advantages of this arrangement are the lower capacitances of the device and the absence of wired connections between die and external terminals, drastically reducing the parasitic resistances and inductances of the device [37], [41].

Simple processes such as soldering become decisive in the operation of the converter, as in the case of the GaN transistors used in this paper, where most of the heat lost in the switch is dissipated on the printed circuit board through the terminals.

Moreover, despite guaranteeing lower switching losses and thus allowing higher switching frequencies, the lower capacitances of the GaN semiconductors also make them more sensitive to the parasitic components of the circuit in which they are inserted. In fact, as the switching frequency increases, the parasitic components inserted in the current path become 
the limiting factor [42]. As demonstrated by [42], a 1.2 $\mathrm{nH}$ difference in the parasitic inductance in series with the switches of a synchronous buck can cause up to $75 \%$ increase in the peak voltage applied to the main switch of the converter.

Techniques such as the use of multilayer printed circuit boards and the insertion of decoupling capacitors under the switches are recommended by manufacturers in order to minimize the effects of circuit's parasitic inductances [38], [42].

\section{TECHNOLOGY COST}

One of the factors that determines the characteristics and, specially the cost of $\mathrm{GaN}$ transistors is the crystalline substrate in which the layers of $\mathrm{GaN}$ and other materials that constitute such devices are deposited [43]. Due to the compatibility of atomic structures, GaN substrates are the ideal choice for use in the fabrication process. However, the availability of material and manufacturing costs makes the use of GaN substrates uncommon [3]. In applications such as LEDs and RF transistors, sapphire substrates are widely used [44]. However, due mainly to its low thermal conductivity, this material is not commonly applied in transistors for power electronics. SiC on the other hand, presents excellent thermal and electrical properties [26]. Its cost, however, is quite high. In the last years, there has been an investment in the research and development of GaN semiconductors with $\mathrm{Si}$ substrates, allowing cost reduction by using the existing Si semiconductor production structure [3]. For this reason, the majority of commercially available GaN transistors is, nowadays, made with Si substrates.

Figure 3 highlights the key characteristics of $\mathrm{Si}$ and $\mathrm{SiC}$ as substrate for producing GaN HEMTs. Outer rings represent better characteristics for device fabrication.

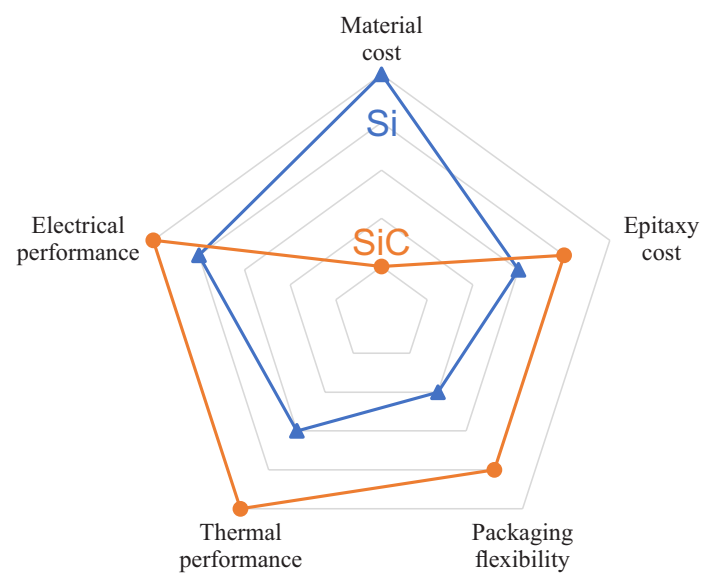

Fig. 3. Characteristics of $\mathrm{Si}$ and $\mathrm{SiC}$ as substrate for $\mathrm{GaN}$ transistors.

\section{PERFORMANCE COMPARISON}

This section presents a comparison between $\mathrm{Si}$ and GaN devices in a family of synchronous buck converters used as drivers for a high power LED.

A previous version of this work was published by the authors in [45]. For this paper, the loss analysis was redone using the SIMETRIX/Simplis simulator due to its "efficiency analysis" tool.

\section{A. Power Topology}

The converter used in this work is a synchronous buck converter operating in continuous conduction mode (CCM). Five different switching frequencies were selected, $100 \mathrm{kHz}$, $250 \mathrm{kHz}, 500 \mathrm{kHz}, 750 \mathrm{kHz}$ and $1 \mathrm{MHz}$. Figure 4 shows the converter circuit.

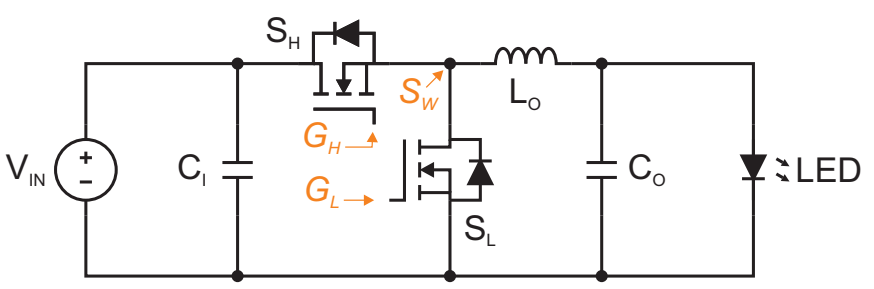

Fig. 4. Synchronous buck converter with LED load.

In order to establish a fair comparison between $\mathrm{Si}$ and $\mathrm{GaN}$ devices, two identical converters were built for each switching frequency, one with Si switches and one with GaN transistors.

Table II presents the main parameters of each converter. A Bridgelux BXRC-50C4000-F-24 power LED was used as load in all the cases.

TABLE II

Converters Specifications

\begin{tabular}{lcc}
\hline Parameter & Symbol & Value \\
\hline Input voltage (V) & $V_{I N}$ & 48 \\
\hline Output voltage (V) & $V_{O U T}$ & 28.3 \\
\hline Output current (A) & $I_{O U T}$ & 0.8 \\
\hline Output power $(\mathrm{W})$ & $P_{O U T}$ & 22.6 \\
\hline Switching frequency $(\mathrm{kHz})$ & $f_{S W}$ & $100-1000$ \\
\hline Inductor current ripple $(\%)$ & $\Delta I L_{O}$ & 30 \\
\hline Output voltage ripple $(\%)$ & $\Delta V_{O}$ & 1 \\
\hline
\end{tabular}

The Si-based converters use the IRF7492 MOSFET from International Rectifier while the $\mathrm{GaN}$ switches used in the prototypes are the enhancement mode EPC2012 from Efficient Power Conversion. These devices were selected because of their similarity, especially regarding the voltages and currents capabilities. Table III shows the main parameters of the semiconductors.

TABLE III

Switches Specifications

\begin{tabular}{lcc}
\hline Parameter & IRF7492 & EPC2012 \\
\hline Drain-source voltage $(\mathrm{V})$ & 200 & 200 \\
\hline Continuous drain current $(\mathrm{A})$ & 3.7 & 3 \\
\hline Maximum on-resistance $(\mathrm{m} \Omega)$ & 79 & 100 \\
\hline Typical on-resistance $(\mathrm{m} \Omega)$ & 64 & 70 \\
\hline Total gate charge $(\mathrm{nC})$ & 39 & 1.5 \\
\hline Package & SO8 & LGA \\
\hline
\end{tabular}

In the synchronous buck converter, the switches operate in a complementary way with a dead time between the turn-off of one switch and the turn-on of the other. During this short period of time, current flows through the intrinsic diode of the low-side transistor. Gallium nitride devices are known for the lack of a p-n junction intrinsic body diode, but instead, they conduct current through the channel when reversed biased. This characteristic provides zero reverse recovery losses, but 
adds a higher voltage drop (approximately twice the voltage drop of Si body diodes) when conducting during this interval.

In order to investigate the effects of this behavior in the converter performance, each prototype was tested with and without an external diode (MBR2H100 from On Semiconductor) connected in parallel with the low-side switch. Besides, two different dead time values were tested in each case, $25 \mathrm{~ns}$ and $50 \mathrm{~ns}$.

The inductor and the input and output capacitors of the converters were designed according to the parameters presented before and the closest commercially available value was chosen in each case. For simplicity, the input capacitor value was set to match the output one.

The same printed circuit board (PCB) layout was used for both technologies at all frequencies, in order to minimize possible mismatches caused by parasitic components of the tracks, such as resistances and inductances. Due to different voltage levels of gate drivers, two separate PCBs were made for them. The connections between the driver board and the converter itself were made using spring-loaded pins. Figure 5 shows the built converters for $\mathrm{Si}$ (top) and GaN (bottom). As it can be observed, a generic footprint that can fit both SO8 and LGA packages was used for the transistors.
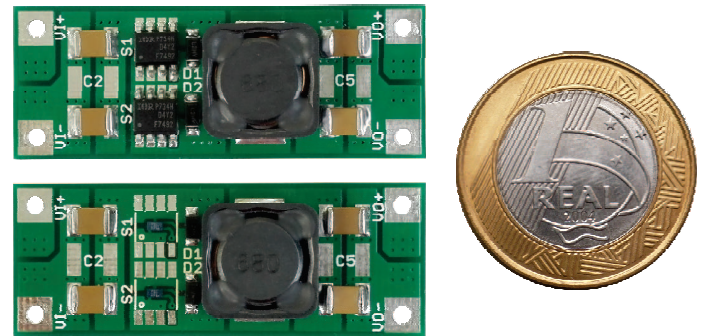

Fig. 5. Converter prototypes using $\mathrm{Si}$ (top) and GaN (bottom).

\section{B. Driver Circuit}

Two complementary PWM signals were used to drive the switches. These signals were generated by a Texas Instruments F28377S Digital Signal Processor with selectable frequency, duty cycle and dead time between both signals. The high precision PWM module was used to ensure accurate timings even at high frequencies. The above-mentioned parameters were set manually prior to operation in order to obtain the right output power at the load.

The silicon-based driver circuit uses the MAX15019 IC from Maxim Integrated with an external bootstrap diode used to reduce power dissipation inside the IC package. The supply voltage for the $\mathrm{Si}$ gate driver is $10 \mathrm{~V}$. For the GaN driver, a LM5113 from National Semiconductor was chosen. This IC is specifically designed for enhancement mode GaN switches, as it provides a regulated high-side voltage to avoid damage to the semiconductors as the output load increases. The supply voltage for this driver is $5 \mathrm{~V}$.

As stated earlier, the driver board was separated from the power board to keep the same layout. The layouts for the driver boards were designed to be as similar as possible. Figure 6 presents the gate drivers' circuits.

\section{Measurement Setup}

The overall efficiency was measured with a Yokogawa WT1800 Precision Power Analyzer, while the temperatures were recorded with a Fluke Ti32 Thermal Imaging Camera. The power consumption of the drivers was not considered.

The results were taken after thermal stabilization, which occurs usually after two minutes of operation. The only exceptions were the $\mathrm{Si}$ prototypes at $750 \mathrm{kHz}$ and $1 \mathrm{MHz}$ in which the high-side transistor reached a temperature that could potentially damage the device, so the test was stopped and the data logged when this switch temperature exceeded $100^{\circ} \mathrm{C}$. No heatsink or air cooling system was used in any of the prototypes.
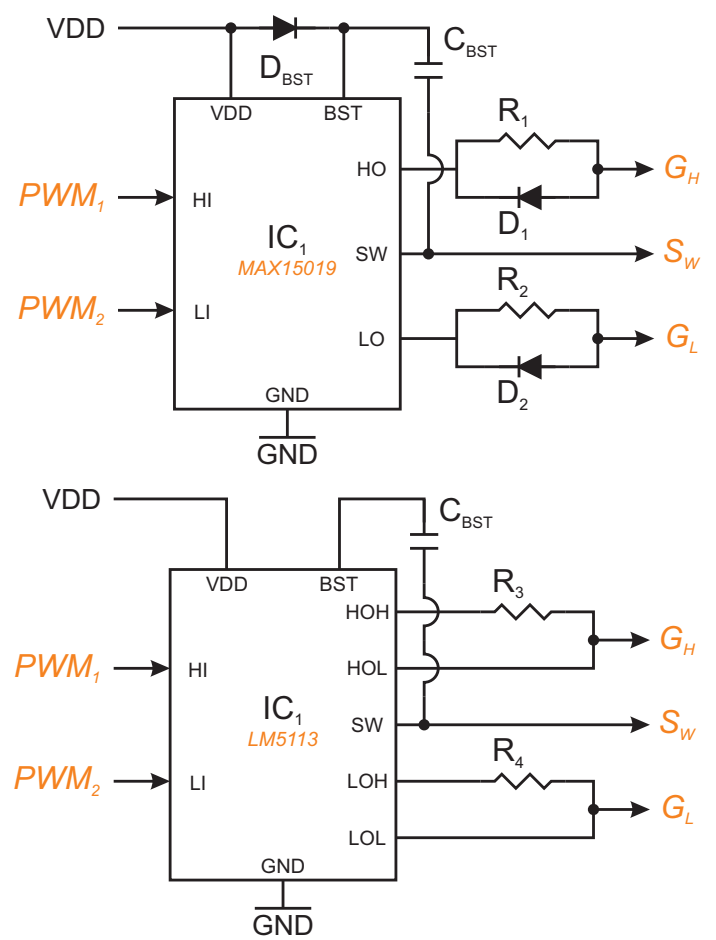

Fig. 6. Si (top) and GaN (bottom) driver circuits.

\section{Experimental Results}

Figure 7 shows the efficiency plots for the converters without and with the parallel diode, respectively. At $100 \mathrm{kHz}$, both semiconductors presented very similar performance. At higher frequencies however, where the switching losses are dominant, GaN devices exhibit better efficiency.

Furthermore, not only the GaN-based converters present higher efficiency in almost all scenarios, but also the performance decay when increasing the switching frequency is less significant in this type of semiconductor. Over the entire frequency range, from $100 \mathrm{kHz}$ to $1 \mathrm{MHz}$, the difference between the highest and the lowest efficiency with $\mathrm{GaN}$ was only $2.3 \%$ in the worst case, with parallel diode and a 25 ns dead time. Without external diode, the difference was only $1.8 \%$ for the same dead time, yielding that despite $\mathrm{GaN}$ transistors have a higher reverse voltage drop than $\mathrm{Si}$, the benefits of not having reverse recovery losses overcome this issue for applications where the switch has to conduct current reverse biased for a short period of time. For the Si-based converters, the efficiency decay was $5.4 \%$ and $4.5 \%$ under the 
same conditions.
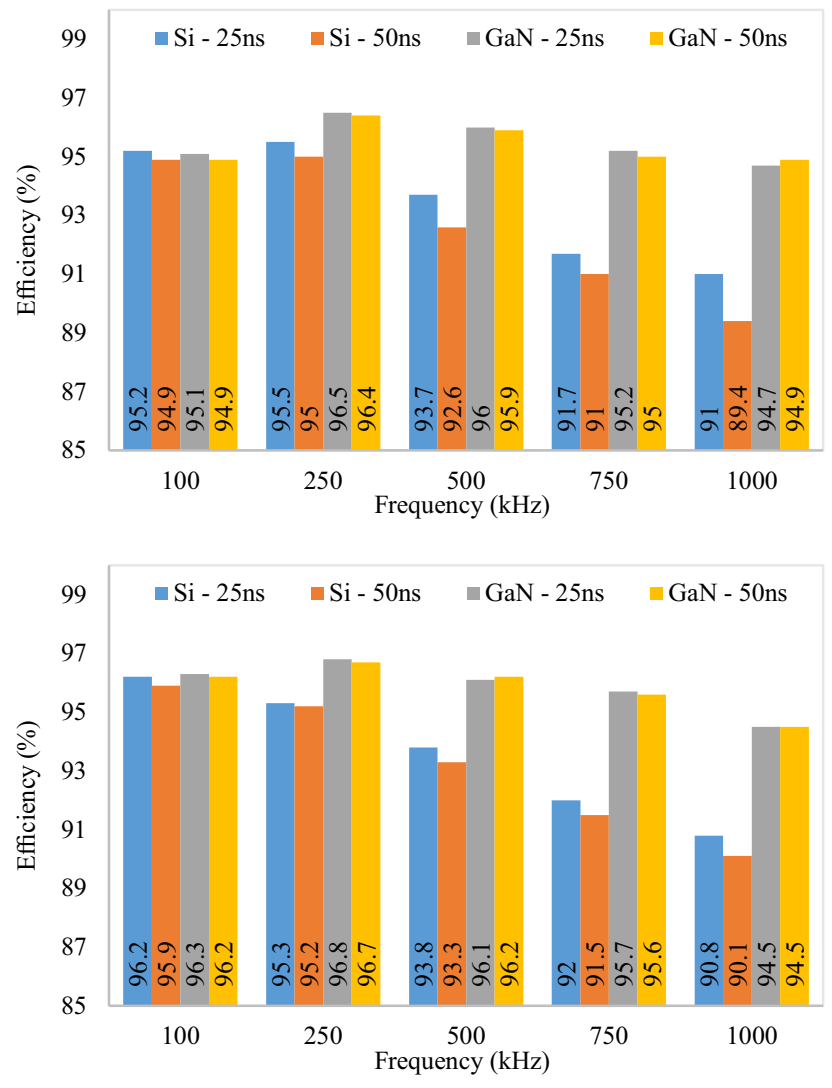

Fig. 7. Efficiency results of the tested converters without (top) and with (bottom) parallel diode.

\section{E. Loss Analysis}

The development of analytical models for GaN transistors is currently a key topic for high frequency converters. Different models with different levels of complexity were demonstrated in the past few years [41], [46]-[48]. Factors such as switching frequency, converter topology and parasitic elements play a major role in the circuit's behavior, directly impacting the model. This result in models that are only suited for one application and/or switching frequency.

As demonstrated by [47], the insertion of current and voltage probes in the circuit to measure the power loss, adds parasitic components into the power loop, modifying the switching behavior. For this reason, probes for measuring the dissipated power in each element of the converter were not included in the PCB. Thus, the power loss breakdown was obtained by simulation. SIMetrix/SIMPLIS simulator was chosen in order to obtain a better approximation of the components models near the operation point. SPICE models provided by the component manufacturers were used to extract the parameters used in simulation. The gate driver circuits were also modeled. Figure 8 presents the simulation results of the converter in one of the four tested cases, without the diode in parallel with the low side switch and a dead time of $25 \mathrm{~ns}$. The absolute error between the simulation and experimental results was below $4.5 \%$ for all cases with an average of $2.65 \%$. The components temperature was not considered in the simulation. As can be seen in Figure 8, the losses of the inductor play a major role in the overall efficiency for both $\mathrm{Si}$ and $\mathrm{GaN}$ switches at low frequencies, while switching losses become more pronounced as the frequency increases, especially in the Si-based converter. This yields that, despite having less on-resistance than $\mathrm{GaN}$, the parasitic capacitances and inductances of the $\mathrm{Si}$ device result in decreasing the converter efficiency. Furthermore, in the GaN-based converter, the losses are better distributed in the circuit, especially at higher frequencies.

\section{CONCLUSIONS}

Large bandgap semiconductors, such as SiC and especially $\mathrm{GaN}$, have emerged in recent years as possible substitutes for $\mathrm{Si}$ devices so that power electronics can continue to exceed limits and increase the performance of static converters. In this way, higher power densities, higher operating frequencies and lower volumes can be achieved without sacrificing system efficiency.

Unlike Si devices, GaN semiconductors are still in their early stages of development, and still have a long way to go, both in terms of performance improvements and manufacturing costs. Despite having virtually no participation in the power electronics market, GaN semiconductors are already present in the academic environment in many applications. Their characteristics such as higher operating temperatures, lower intrinsic capacitances and higher blocking voltages capabilities make them promising candidates to replace $\mathrm{Si}$ in the next few years.

In addition, issues that are still little explored at local level, like layout choices and their implications on the final product still need to be improved. With this, the problems faced in the transition between switches from $\mathrm{Si}$ to $\mathrm{GaN}$ can be reduced.

Regarding the LED driver, the experimental comparison showed superior performance of $\mathrm{GaN}$ transistors in almost all tested cases. Despite having a higher on-resistance than the IRF7492, the smaller capacitances of the EPC2012 demonstrated that the switching losses play a major role in the overall efficiency of the converter, especially at higher frequencies.

The presented results highlight the potential of $\mathrm{GaN}$ for taking the silicon place in the power electronics market in the future. As the demand for more compact and efficient converter increases, the need for high performance devices also grows. Besides, the silicon technology is approaching its theoretical limits. Therefore, it creates an encouragement for the insertion of $\mathrm{GaN}$ devices in the market in the near future.

\section{ACKNOWLEDGEMENTS}

The authors gratefully acknowledge EPCOS Brazil and SIMPLIS Technologies, Inc. for their support during the development of this work. This work was supported by the Brazilian government through PROEX program, PRPGP/UFSM, INCT-GD, CNPq proc 465640/2014-1, CAPES proc 23038.000776/2017-54, FAPERGS proc 17/2551-0000517-1 and by the Spanish government under grant ENE2013-41491-R. 

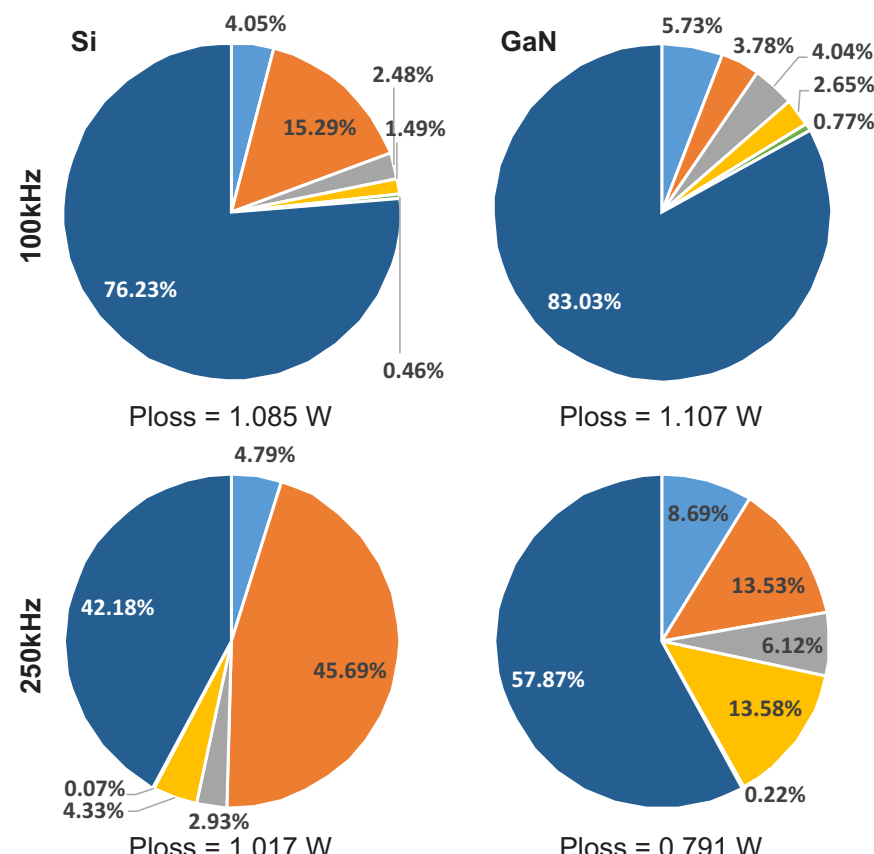

Ploss $=1.017$

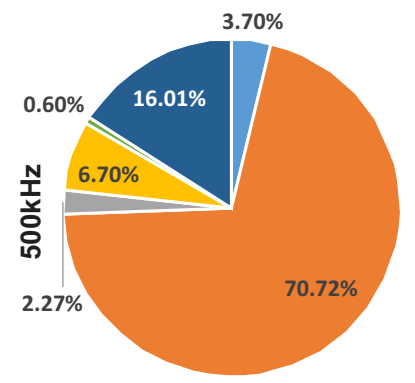

Ploss $=1.424 \mathrm{~W}$
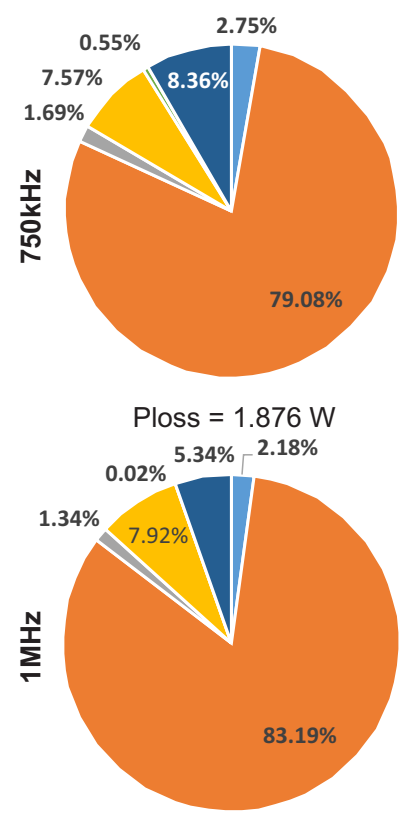

Ploss $=2.034 \mathrm{~W}$

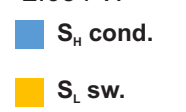

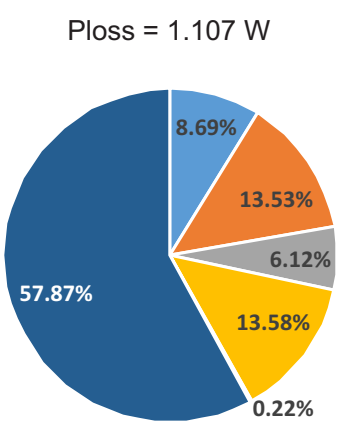

Ploss $=0.791 \mathrm{~W}$

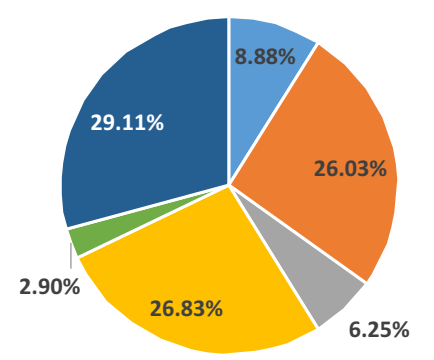

Ploss $=0.904 \mathrm{~W}$

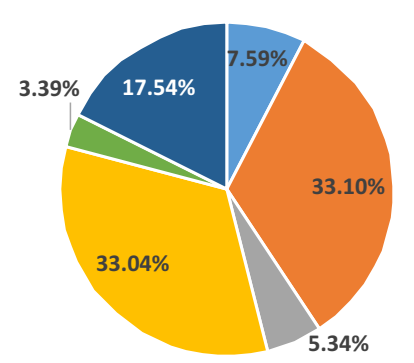

Ploss $=1.085 \mathrm{~W}$

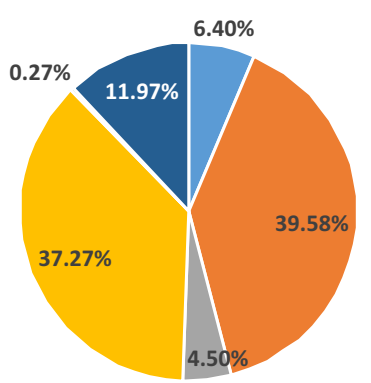

Ploss $=1.198 \mathrm{~W}$

$\mathrm{S}_{\mathrm{H}}$ sw. $\quad \mathrm{S}_{\mathrm{L}}$ cond.

$\mathrm{C}_{1}+\mathrm{C}_{\mathrm{o}}$

$\mathrm{L}_{\mathrm{o}}$

Fig. 8. Losses distribution. $S_{H}$ cond. and $S_{L}$ cond. are the conduction losses in the high and low side switches, respectively; $S_{H} s w$. and $S_{L} s w$. are the switching losses in the high and low side switches, respectively; $C_{I}+C_{O}$ is the total loss in the capacitors and $L_{O}$ is the total inductor loss.

\section{REFERENCES}

[1] M. Duffy, "The mercury-arc rectifier and supply to electric railways", Engineering Science \& Education Journal, vol. 4, no. 4, pp. 183-192, Aug. 1995.

[2] B. Baliga, "Trends in power semiconductor devices", IEEE Transactions on Electron Devices, vol. 43, no. 10 , pp. 1717-1731, Oct. 1996.

[3] A. Lidow, J. Strydom, M. de Rooij, D. Reusch, GaN Transistors for Efficient Power Conversion, 2 ed., John Wiley \& Sons Ltd, Chichester, Jul. 2014.

[4] T. D. Heidel, P. Gradzki, "Power devices on bulk gallium nitride substrates: An overview of ARPA-E's SWITCHES program”, in IEEE International Electron Devices Meeting, pp. 2.7.1-2.7.4, 2014.

[5] P. Gueguen, "How power electronics will reshape to meet the $21 \mathrm{st}$ century challenges?", in IEEE International Symposium on Power Semiconductor Devices \& IC's (ISPSD), pp. 17-20, 2015.

[6] H. Ueda, M. Sugimoto, T. Uesugi, T. Kachi, "Wide-bandgap semiconductor devices for automobile applications", in CS MANTECH Conference, pp. 3740, 2006.

[7] Y. Wu, M. Jacob-Mitos, M. L. Moore, S. Heikman, “A 97.8\% Efficient GaN HEMT Boost Converter With 300-W Output Power at $1 \mathrm{MHz}$ ", IEEE Electron Device Letters, vol. 29, no. 8, pp. 824-826, Aug. 2008.

[8] J. Xue, L. Cong, H. Lee, "A 130 W 95\%-efficiency $1 \mathrm{MHz}$ non-isolated boost converter using PWM zerovoltage switching and enhancement-mode GaN FETs", in IEEE Applied Power Electronics Conference and Exposition (APEC), pp. 471-475, 2014.

[9] H. Wang, Investigation of Power Semiconductor Devices for High Frequency High Density Power Converters. PhD Thesis, Virginia Polytechnic Institute and State University, Blacksburg, USA, 2007.

[10] L. M. Tolbert, B. Ozpineci, S. K. Islam, M. S. Chinthaval, "Wide bandgap semiconductors for utility applications", in Power and Energy Systems (PES), pp. $1-5,2003$.

[11] M. J. Scott, K. Zou, E. Inoa, R. Duarte, Y. Huang, J. Wang, "A Gallium Nitride switched-capacitor power inverter for photovoltaic applications", in IEEE Applied Power Electronics Conference and Exposition (APEC), pp. 46-52, 2012.

[12] Y. Zhou, L. Liu, H. Li, "A High-Performance Photovoltaic Module-Integrated Converter (MIC) Based on Cascaded Quasi-Z-Source Inverters (qZSI) Using eGaN FETs", IEEE Transactions on Power Electronics, vol. 28, no. 6, pp. 2727-2738, Jun. 2013.

[13] C.-Y. Lin, Y.-C. Liu, H.-J. Chiu, Y.-K. Lo, C.-Y. Lin, P.-J. Tseng, S.-J. Cheng, "Study on an interleaved buck power factor corrector with gallium nitride field effect transistor and integrated inductor", IET Power Electronics, vol. 7, no. 10, pp. 2506-2516, Oct. 2014.

[14] Z. Liu, F. C. Lee, Q. Li, Y. Yang, "Design of GaNBased MHz Totem-Pole PFC Rectifier", IEEE Journal of Emerging and Selected Topics in Power Electronics, vol. 4, no. 3, pp. 799-807, Sep. 2016. 
[15] D. Cucak, M. Vasic, O. Garcia, J. A. Oliver, P. Alou, J. A. Cobos, "Application of eGaN FETs for highly efficient Radio Frequency Power Amplifier", in International Conference on Integrated Power Electronics Systems (CIPS), vol. 9, pp. 1-6, 2012.

[16] M. A. de Rooij, J. T. Strydom, "eGaN FETs in Low Power Wireless Energy Converters", ECS Transactions, vol. 50, no. 3, pp. 377-388, Mar. 2013.

[17] W. Chen, R. A. Chinga, S. Yoshida, J. Lin, C. Chen, W. Lo, “A 25.6 W 13.56 MHz wireless power transfer system with a $94 \%$ efficiency GaN Class-E power amplifier", in IEEE/MTT-S International Microwave Symposium Digest, pp. 1-3, 2012.

[18] J. Glaser, "How GaN Power Transistors Drive HighPerformance Lidar: Generating ultrafast pulsed power with GaN FETs", IEEE Power Electronics Magazine, vol. 4, no. 1, pp. 25-35, Mar. 2017.

[19] T. B. Soeiro, T. K. Jappe, W. M. dos Santos, D. C. Martins, M. L. Heldwein, "Propulsion and battery charging systems of an all-electric boat fully constructed with interleaved converters employing interphase transformers and Gallium Nitride (GaN) power FET semiconductors", in IEEE Applied Power Electronics Conference and Exposition (APEC), pp. 3212-3217, 2014.

[20] F. Medjdoub, M. Zegaoui, D. Ducatteau, N. Rolland, P. Rolland, "First AlN/GaN HEMTs power measurement at $18 \mathrm{GHz}$ on Silicon substrate", in Device Research Conference, vol. 98, pp. 219-220, 2011.

[21] R. Stevenson, "Power electronics' cool new flavor", IEEE Spectrum, vol. 53, no. 4, pp. 11-12, Apr. 2016.

[22] S. Sze, K. K. Ng, Physics of Semiconductor Devices, 3 ed., John Wiley \& Sons, Inc., Hoboken, Oct. 2007.

[23] B. Van Zeghbroeck, Principles of Semiconductor Devices and Heterojunctions, 1 ed., Prentice Hall, 2009.

[24] A. Elasser, T. Chow, "Silicon carbide benefits and advantages for power electronics circuits and systems", Proceedings of the IEEE, vol. 90, no. 6, pp. 969-986, Jun. 2002.

[25] J. Hudgins, G. Simin, E. Santi, M. Khan, "An assessment of wide bandgap semiconductors for power devices", IEEE Transactions on Power Electronics, vol. 18, no. 3, pp. 907-914, May 2003.

[26] D. C. Sheridan, D. Y. Lee, A. Ritenour, V. Bondarenko, J. Yang, C. Coleman, "Ultra-Low Loss 600V1200V GaN Power Transistors for High Efficiency Applications 650V GaN Device Performance and Comparisons", in International Exhibition and Conference for Power Electronics, Intelligent Motion, Renewable Energy and Energy Management (PCIM Europe), pp. 318-324, 2014.

[27] A. Guerra, J. Zhang, "GaN Power Devices for Micro Inverters", Power Electronics Europe, no. 4, pp. 28 31, Jun. 2010.

[28] U. Mishra, P. Parikh, Yi-Feng Wu, "AlGaN/GaN HEMTs-an overview of device operation and applications", Proceedings of the IEEE, vol. 90, no. 6, pp. 1022-1031, Jun. 2002.
[29] R. S. Pengelly, S. M. Wood, J. W. Milligan, S. T. Sheppard, W. L. Pribble, "A Review of GaN on SiC High Electron-Mobility Power Transistors and MMICs", IEEE Transactions on Microwave Theory and Techniques, vol. 60, no. 6, pp. 1764-1783, Jun. 2012.

[30] T. Mimura, N. Yokoyama, H. Kusakawa, K. Suyama, M. Fukuta, "MP-A4 GaAs MOSFET for low-power high-speed logic applications", IEEE Transactions on Electron Devices, vol. 26, no. 11, pp. 1828-1828, Nov. 1979.

[31] G. Meneghesso, G. Verzellesi, F. Danesin, F. Rampazzo, F. Zanon, A. Tazzoli, M. Meneghini, E. Zanoni, "Reliability of GaN High-ElectronMobility Transistors: State of the Art and Perspectives", IEEE Transactions on Device and Materials Reliability, vol. 8, no. 2, pp. 332-343, Jun. 2008.

[32] H. Sano, K. Otobe, Y. Tateno, N. Adachi, S. Mizuno, A. Kawano, J. Nikaido, S. Sano, “A 1.8-2.3GHz Wideband and Compact Power Amplifier Module Using AlGaN/GaN HEMTs", in Asia-Pacific Microwave Conference Proceedings, vol. 2, pp. 1-4, 2005.

[33] M. Murphy, "Cascode Circuit Employing a Depletionmode, GaN-based FET", US Patent 7,501,670 B2, Mar. 10, 2009.

[34] N. Ikeda, S. Kaya, J. Li, T. Kokawa, Y. Satoh, S. Katoh, "High-power AlGaN/GaN HFETs on Si substrates", in International Power Electronics Conference (IPEC), 34, pp. 1018-1022, 2010.

[35] N. Kaneko, O. Machida, M. Yanagihara, S. Iwakami, R. Baba, H. Goto, A. Iwabuchi, "Normallyoff AlGaN/GaN HFETs using NiOx gate with recess", in IEEE International Symposium on Power Semiconductor Devices \& IC's (ISPSD), pp. 25-28, 2009.

[36] M. Rodriguez, Y. Zhang, D. Maksimovic, "HighFrequency PWM Buck Converters Using GaN-on-SiC HEMTs", IEEE Transactions on Power Electronics, vol. 29, no. 5, pp. 2462-2473, May 2014.

[37] J. Zhang, Bidirectional DC-DC Power Converter Design Optimization, Modeling and Control. PhD Thesis, Virginia Polytechnic Institute and State University, Blacksburg, USA, 2008.

[38] D. Reusch, M. de Rooij, "Evaluation of gate drive overvoltage management methods for enhancement mode gallium nitride transistors", in IEEE Applied Power Electronics Conference and Exposition (APEC), pp. 2459-2466, 2017.

[39] X. Huang, Z. Liu, Q. Li, F. C. Lee, "Evaluation and Application of $600 \mathrm{~V}$ GaN HEMT in Cascode Structure", IEEE Transactions on Power Electronics, vol. 29, no. 5, pp. 2453-2461, May 2014.

[40] G. Deboy, W. Kaindl, U. Kirchner, M. Kutschak, E. Persson, M. Treu, "Advanced Silicon Devices - Applications and Technology Trends", in IEEE Applied Power Electronics Conference and Exposition (APEC), pp. 1-28, 2015. 
[41] O. Khan, F. F. Edwin, Weidong Xiao, "Loss modeling for enhancement mode gallium nitride field efect transistor in power converter applications", in Annual Conference of the IEEE Industrial Electronics Society (IECON), pp. 7181-7186, 2013.

[42] D. Reusch, J. Strydom, "Understanding the Effect of PCB Layout on Circuit Performance in a HighFrequency Gallium-Nitride-Based Point of Load Converter", IEEE Transactions on Power Electronics, vol. 29, no. 4, pp. 2008-2015, Apr. 2014.

[43] D. Smith, S.-C. Tsen, B. Sverdlov, G. Martin, H. Morkoç, "Stacking mismatch boundaries in GaN: Implications for substrate selection", Solid-State Electronics, vol. 41, no. 2, pp. 349-352, Feb. 1997.

[44] S. A. Kukushkin, A. V. Osipov, V. N. Bessolov, B. K. Medvedev, V. K. Nevolin, K. A. Tcarik, "Substrates for epitaxy of gallium nitride: New materials and techniques", Reviews on Advanced Materials Science, vol. 17, no. 1-2, pp. 1-32, Apr. 2008.

[45] R. R. Duarte, G. F. Ferreira, M. A. Dalla Costa, J. M. Alonso, "Performance comparison of $\mathrm{Si}$ and $\mathrm{GaN}$ transistors in a family of synchronous buck converters for LED lighting applications", in IEEE Industry Applications Society Annual Meeting, pp. 17, 2016.

[46] K. Shah, K. Shenai, "Simple and Accurate Circuit Simulation Model for Gallium Nitride Power Transistors", IEEE Transactions on Electron Devices, vol. 59, no. 10, pp. 2735-2741, Oct. 2012.

[47] J. Brandelero, B. Cougo, T. Meynard, N. Videau, “A non-intrusive method for measuring switching losses of GaN power transistors", in Annual Conference of the IEEE Industrial Electronics Society (IECON), pp. 246-251, 2013.

[48] W. Kangping, Y. Xu, Z. Xiangjun, Y. Xiaoling, L. Hongchang, G. Yixuan, G. Bing, M. Huan, "Analytical loss model of low voltage enhancement mode GaN HEMTs", in IEEE Energy Conversion Congress and Exposition (ECCE), pp. 100-105, 2014.

\section{BIOGRAPHIES}

Renan Rodrigo Duarte, born in Santo Augusto, Brazil, in 1992. He received his bachelor and master degree in Electrical Engineering from the Federal University of Santa Maria in 2015 and 2017, respectively. He is currently working towards his Doctorate degree at the same institution. He is member of the IEEE and is currently the vice-chair of the Student Branch and IAS Student Branch Chapter of IEEE at the Federal University of Santa Maria.

Guilherme Farias Ferreira, born in Quaraí, Brazil, in 1994. He is currently working toward the B.S. degree in electrical engineering at the Federal University of Santa Maria (UFSM), Santa Maria, Brazil. He took part in industrial activities with
STEMAC Group of Generators, Porto Alegre, Brazil, and since 2011, he has been with the Electronic Ballast Research Group (GEDRE), UFSM, where he is currently a Researcher. His research activities include the illumination field, mainly involving the use of LEDs.

Marco Antonio Dalla Costa, born in Santa Maria, Brazil, in 1978. He received the B.S. and M.Sc. degrees in electrical engineering from the Federal University of Santa Maria, Brazil, in 2002 and 2004, respectively, and the Ph.D. degree (with honors) in electrical engineering from the University of Oviedo, Gijón, Spain, in 2008. From 2008 to 2009 he was Associate Professor at the Universidade de Caxias do Sul, Brazil. Since 2009 he is Associate Professor at the Federal University of Santa Maria, Brazil. Dr. Dalla Costa is coauthor of more than 50 journal papers and more than 100 international conference papers, he is holder of 2 Spanish patents, and he is the Vice-Chair of the Industrial Lighting and Displays Committee (ILDC) from IAS-IEEE. He also serves as reviewer for several IEEE Journal and Conferences in the field of power electronics. His research interests include $\mathrm{dc} / \mathrm{dc}$ converters, power factor correction, lighting systems, highfrequency electronic ballasts, discharge-lamp modeling, lightemitting-diode systems, renewable energy systems, and solid state transformers.

Carlos Henrique Barriquello, born in Três Passos, RS, Brazil, in 1984. He received the B.Sc., M.Sc. and Ph.D. degrees in electrical engineering from Federal University of Santa Maria in 2007, 2009 and 2012, respectively. Since 2012, he has been Adjunct Professor in the Electronics and Computing Department at the Federal University of Santa Maria, Brazil. Also, he has been a Researcher with the Electronic Ballast Research Group (GEDRE), Federal University of Santa Maria, since 2008. His research interests include embedded and real-time systems, wireless sensor and actuator networks, lighting systems, and visible light communications.

José Marcos Alonso, received the M. Sc. Degree and Ph. D. both in electrical engineering from the University of Oviedo, Spain, in 1990 and 1994 respectively. Since 2007, he is a full Professor of the Electrical Engineering Department of the University of Oviedo. Prof. Alonso is co-author of more than 370 journal and conference publications, including 90 publications in highly referenced journals. His research interests include electronic lighting, dc-dc converters, power factor correction, resonant inverters and power electronics in general. He is the holder of 7 Spanish patents. Prof. Alonso holds 7 IEEE awards. He serves as an Associate Editor of the IEEE Transactions on Power Electronics and IEEE Journal on Emerging and Selected Topics on Power Electronics. He is currently Chair of the IEEE IAS Industrial Lighting and Displays Committee. He is also serving as Chair of the IAS Awards Department and IAS Newsletter Editor. 